\title{
The Simulation Study on Optimal Power Control of Grid-side Converter Used in Full Power Wind Turbine
}

\author{
Xiangming Wang and Jiansheng Zhou \\ School of Shenyang University of Technology ,Liaoning110178, China
}

\begin{abstract}
For wind power full power inverter power control, as the power system switch device IGBT is established, and the application of SVPWM modulation technology and PI adjustment control strategy, in order to achieve the goal of power optimization. The PI control can realize power four quadrant transform, system dynamic response well and make the system enter the steady-state reduce the static error so that the steady state performance improvement. Make constant DC voltage in order to obtain good input performance, provide channels for rotor converter bi-directional power flow, at the same time realize the gird side variable power factor operation or unit power factor operation, and has carried on the Matlab/Simulink, the simulation results verify the validity of the analysis and the feasibility of the system.
\end{abstract}

Keywords-component: wind power generato; converter; power optimization

\section{INTRODUCTION}

Wind power generation as an integral part of the energy structure. At present, the capacity of the wind power installed in China is gradually increasing, and it has very important significance to carry out the research of wind power grid operation and power optimization control technology. The Grid-side converter is an important part of the wind turbine, which is the two-way flow channel of the system energy. It is also an important part of the adjustment of the power factor of the input power and the stability of the DC bus voltage. With prices down of the power device, the proportion of cost is getting smaller and smaller in the wind power system of the converter. The full power wind power converter have many advantages compared with others: the converter isolated the generator and the power grid, easier to achieve the wind power system through fault. And the converter run in the static synchronous compensator state when the grid fault, which can provide more reactive support. At present, the domestic and foreign wind power researchers have carried out many related research in the field of grid-connected control technology. Reference [1][2], which are mainly research for wind power system and grid side converter control strategy. Reference studied the specific converter coordinate transformation processes, it analyzes the voltage-type PWM rectifier control characteristics.

In this paper, the main control strategy is simulation the grid side converter of full power wind generator. In Matlab/Simulink to set the model and analysis results of the model, then to verify the feasibility and effectiveness of the power optimization scheme of double closed loop based on decoupling.

\section{THE BASIC THEORY OF GRID-SIDE CONVERTER VECTOR CONTROL}

In the wind power system, from the structure of the circuit, the model of grid-side converter described is a voltage-type PWM in this paper. Grid-side structure shown in Figure I:

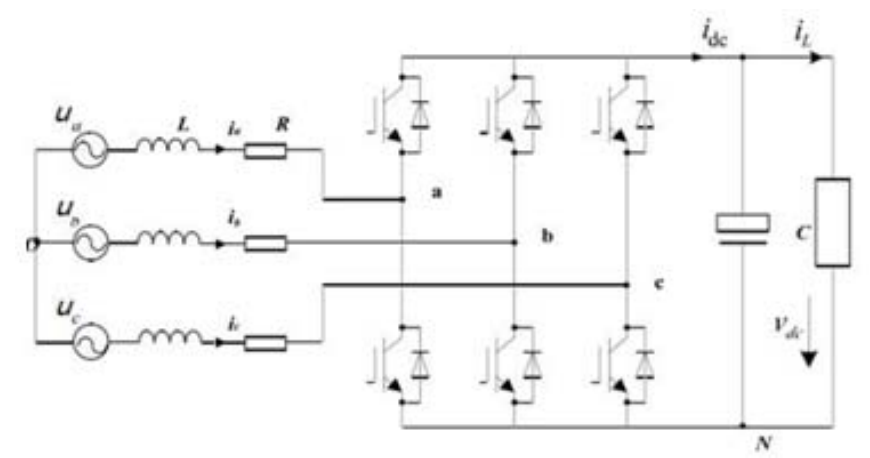

FIGURE I. GRID-SIDE VOLTAGE SOURCE CONVERTER

At present the grid-side converter, most of the switching devices of power system are IGBT. The control of IGBT is adopted SVPWM technique whatever converter running in the rectification and inversion. As the IGBT is always working, which can negligible the three-phase converter input current of harmonic component. Therefore, the SPWM control method is the key to improve the stability of system. Suppose under ideal conditions: grid voltage is balance, circuit switching are ideal device. According to the grid-side converter structure, the following equation can be obtained [4]:

$$
\left\{\begin{array}{l}
u_{a}-i_{a} R-L \frac{d i_{a}}{d t}-S_{a} u_{d c} \\
=u_{b}-i_{b} R-L \frac{d i_{b}}{d t}-S_{b} u_{d c} \\
=u_{c}-i_{c} R-L \frac{d i_{c}}{d t}-S_{c} u_{d c} \\
C \frac{d u_{d c}}{d t}=i_{d c}-i_{L}=S_{a} i_{a}+S_{b} i_{b}+S_{c} i_{c}-i_{L}
\end{array}\right.
$$

In the formula, $i_{a} i_{b} i_{c}$ are the input three phase current of converter; $u_{a} u_{b} u_{c}$ are the three-phase power supply; $i_{L}$ is the DC side load current; $i_{d c}$ is the DC output current; $u_{d c}$ is the 
output DC voltage; $S_{a} S_{b} S_{c}$ are the switching function of the three-phase bridge arm. $S_{i}=1$ is the up IGBT turned on in $i$ phase; $S_{i}=0$ is the down IGBT turned on in $i$ phase. In the three-phase without neutral line system, the sum of three phase current is zero, that is $i_{a}+i_{b}+i_{c}=0$; and the three-phase voltage balance, that is $u_{a}+u_{b}+u_{c}=0$. Make these two conditions into the equation (1), you can get three-phase voltage type PWM converter mathematical model in $d q$ coordinates, as following formula (2) [5],

$$
\left\{\begin{array}{l}
L \frac{d i_{d}}{d t}=-R i_{d}+\omega L i_{q}-S_{d} u_{d c}+u_{d} \\
L \frac{d i_{q}}{d t}=-R i_{q}+\omega L i_{d}-S_{q} u_{d c}+u_{q} \\
C \frac{d u_{d c}}{d t}=\frac{3}{2} S_{d} i_{d}+\frac{3}{2} S_{q} i_{q}-i_{L}
\end{array}\right.
$$

Then simplify control algorithm, application space coordinate transformation, the $\mathrm{d}$-axis of rotating dq coordinate system oriented in the direction of the grid voltage vector us, then the dq component of the grid voltage are $\mathrm{ud}=\mathrm{us}, \mathrm{uq}=0$. Input current satisfaction (3)

$$
\left\{\begin{array}{l}
L \frac{d i_{d}}{d t}=-R i_{d}+\omega L i_{q}+u_{s}-u_{d r} \\
L \frac{d i_{q}}{d t}=-R i_{q}-\omega L i_{d}-u_{q r}
\end{array}\right.
$$

In the formula, $u_{d r}, u_{q r}$ are the $d, q$ components of converter AC side voltage, and $u_{d r}=S_{d} u_{d c}, u_{q r}=S_{q} u_{d c}$. Briefly described above converter as mathematical models and coordinate transformation, in which the space vector theory has matured. So not tired in this paper, you can refer to the literature [6].

\section{CONTROL STRATEGY OF GRID POWER OPTIMIZATION}

Not only to make the grid-side DC voltage stability, but also a relatively fast dynamic response, meanwhile grid-side current must be sine wave and input power factor close to 1 , so as to achieve gird-side power optimization significance. This method is the grid voltage oriented vector control, summarized as: grid voltage through coordinate transformation and for phasing vector, which $i_{d}$ is controlling active current, $i_{q}$ is controlling the reactive power current. The control block is in Figure II.

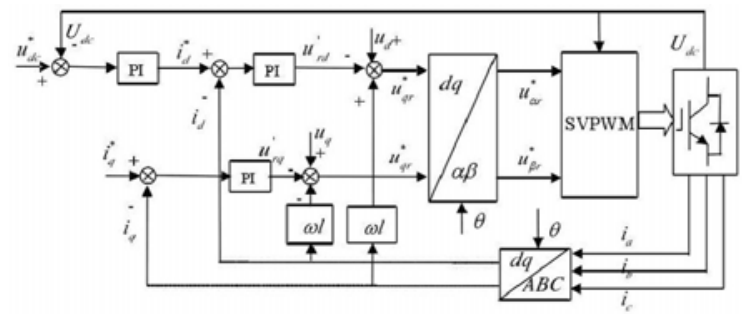

FIGURE II. STRUCTURE OF GRID-SIDE PWM CONVERTER CONTROL SYSTEM
In this paper, the control strategy using a double-closedloop control structure in which the outer voltage loop control three-phase PWM converter of DC-side voltage. In the diagram, the deviation, which is given value (DC voltage) and feedback value, after the PI controller output is $i_{d}{ }^{*}$ as active current given value, its value represent the real power, and the sign determines the active power direction of flow. According to the output current signal of voltage loop, getting the current inner loop to control current. To eliminate $d ; q$ axis current coupling and grid voltage disturbances, so introducing the $\omega L_{i d}$ and $\omega$ $L_{i q}$ of the current feedback to decoupling. To introduce the grid voltage feed-forward compensation for independent control the $d ; q$ axis current. In order to achieve the power factor to be 1 when the system working in rectifier or inverter, it should get the reactive current component $i_{q}{ }^{*}$ for 0 . The system uses PI control, as follows: if $i_{q}{ }^{*}$ is positive, the wind power system to work in a leading power factor, then conveying inductive reactive power to grid power; if $i q^{*}$ is negative, the wind power system in lagging power factor, then system absorb inductive reactive power from the grid .

According to the mathematical model of the converter, we can be got:

$$
\left[\begin{array}{l}
u_{d r} \\
u_{q r}
\end{array}\right]=-\left[\begin{array}{ll}
L p+R & -\omega L \\
\omega L & L p+R
\end{array}\right]\left[\begin{array}{l}
i_{d} \\
i_{q}
\end{array}\right]+\left[\begin{array}{l}
u_{d} \\
u_{q}
\end{array}\right]
$$

The $p$ is differential operator. From the above, the variable of the AC side voltage $q$ and $d$ axis of the converter is coupled with each other, which makes it difficult to design the controller. Therefore, the paper uses the feed-forward decoupling control method. When current is used in the PI regulator, then the equations of $u_{d r}, u_{q r}$;

$$
\left\{\begin{array}{l}
u_{d r}=-\left(K_{i p}+\frac{K_{i l}}{s}\right)\left(i_{d}^{*}-i_{d}\right)-\omega L i_{q}+u_{d} \\
u_{q r}=-\left(K_{i p}+\frac{K_{i l}}{s}\right)\left(i_{q}^{*}-i_{q}\right)-\omega L i_{d}+u_{q}
\end{array}\right.
$$

In the formula, the $K_{i p}$ is the current inner ratio adjustment factor, and $K_{i l}$ is the current inner integral adjustment factor. And $i_{d}{ }^{*}, i_{q}{ }^{*}$ are given value of the active and reactive current of the $i_{d}, i_{q}$. Get formula (5) into (4), then simplification can be obtained (6) and (7):

$$
\begin{gathered}
p\left[\begin{array}{l}
i_{d} \\
i_{q}
\end{array}\right]=\left[\begin{array}{ll}
A & 0 \\
0 & A
\end{array}\right]\left[\begin{array}{l}
i_{d} \\
i_{q}
\end{array}\right]-\frac{K_{i p}+\frac{K_{i l}}{S}}{L}\left[\begin{array}{l}
i_{d}^{*} \\
i_{q}^{*}
\end{array}\right] \\
A=-\frac{R-K_{i p}+\frac{K_{i l}}{S}}{L}
\end{gathered}
$$

In the formula, the algorithm is based on the feed forward control, which makes the current inner loop $i_{d}$ and $i_{q}$ realize 
decoupling. According to the definition of instantaneous active and reactive power, the active and reactive power of the input of the PWM converter in the grid voltage oriented $d q$ coordinate system is the type (8).

$$
\left\{\begin{array}{l}
P=\frac{3}{2}\left(u_{d} i_{d}+u_{q} i_{q}\right)=\frac{3}{2} u_{s} i_{d} \\
Q=\frac{3}{2}\left(u_{q} i_{d}-u_{d} i_{q}\right)=\frac{3}{2} u_{s} i_{q}
\end{array}\right.
$$

When $\mathrm{Q}>0$ the converter output reactive power; when $\mathrm{Q}<0$ the converter output capacitive reactive power. When $\mathrm{P}>0$ the converter works in the rectification state, from the power grid to absorb energy; when $\mathrm{P}<0$ the converter works in the inverter state, the energy from the DC side back to the power grid [8].

\section{Simulation}

According to the theory and literature discussed above, build the network-side converter system and do the research based on Matlab/Simulink platform. The parameters of the grid-side converter system are set as follows: the RMS of the grid voltage is $690 \mathrm{~V}$, the $\mathrm{DC}$ reference voltage is $1100 \mathrm{~V}$, the grid frequency is $50 H Z$, the SVPWM frequency is $2 \mathrm{KHZ}$, the capacitor of the DC side is $0.0368 F$, the filter inductor of the three-phase is $0.00043 \mathrm{H}$ and the equivalent resistance of the AC side is $0.005 \Omega$. The parameters of PI to the inner current feedback loop is set up based on the Reference [9], and $K_{p}=20$, $K_{i}=60$. The parameter of PI to the voltage loop are $K_{p}=20$, $K_{i}=120$. The simulation model is shown in Figure III. The vector control of grid-side achieves the invariant of DC bus voltage and the adjustment of the reactive power through the converter to the system, the double closed loop PI control is shown in Figure IV. Generally, system is operating based on unit power factor no matter the grid-side converter working on rectifier or inverter.

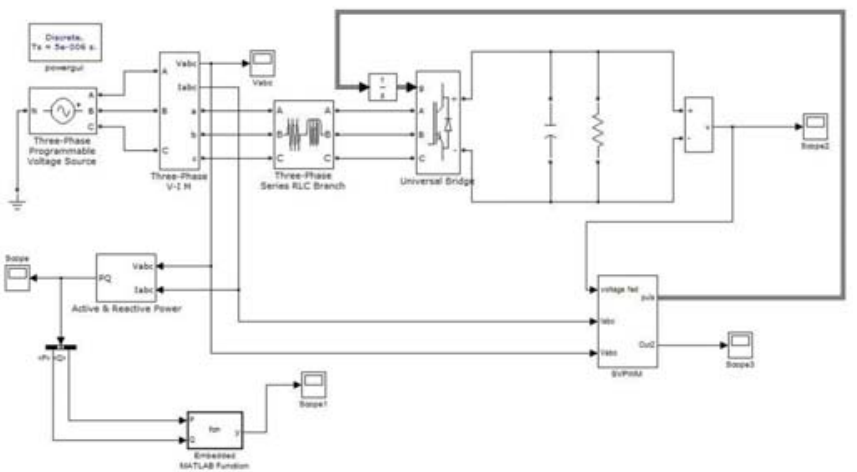

FIGURE III. SIMULATION PROGRAM OF THE GRID-SIDE CONVERTER

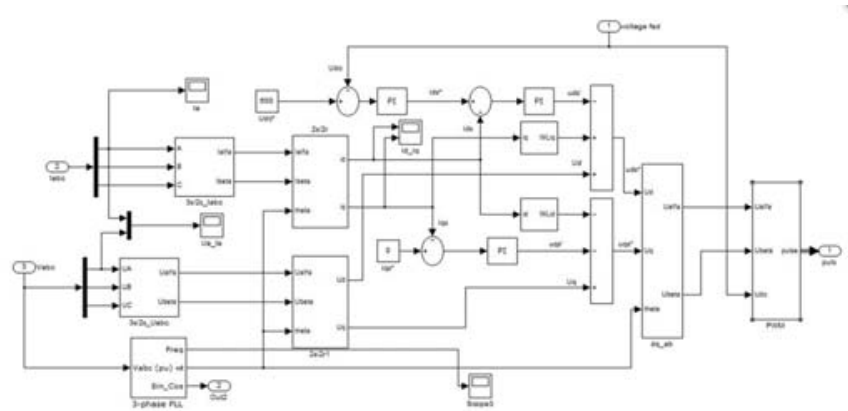

FIGURE IV. SIMULATION PROGRAM OF DOUBLE CLOSED-LOOP CONTROL MODEL

\section{THE VERIFICATION BASED ON EXPERIMENT}

From the analysis of the simulation results, the theoretical value of the system voltage and DC bus voltage are $690 \mathrm{~V}$ and $1100 \mathrm{~V}$ respectively. The simulation result of DC bus voltage is shown in Figure V, it stabilized at the expected value after $0.4 \mathrm{~s}$, this demonstrates that the chosen power optimization strategy can help to maintain the DC bus voltage rapidly and effectively when the system power fluctuates. The power factor curve of grid-side converter is shown in Figure VI. The grid power factor is approximately unity and it can be changed from the proportion of $i_{d}$ and $i_{q}$. With the control strategy, the active power and reactive power become stable after $0.4 \mathrm{~s}$, which is shown in Figure VII. The current curve of $i_{d}$ and $i_{q}$ are shown in Figure VIII. The $i_{q}$ tends to 0 and $i_{d}$ tends to $500 \mathrm{~A}$ after $0.3 \mathrm{~s}$. Grid-side converter starts rectify when it works in subsynchronous operation status and the energy flow from grid to converter as the grid-side converter can achieve the bidirectional flow of the power. On the contrary, the energy flows from converter to grid.

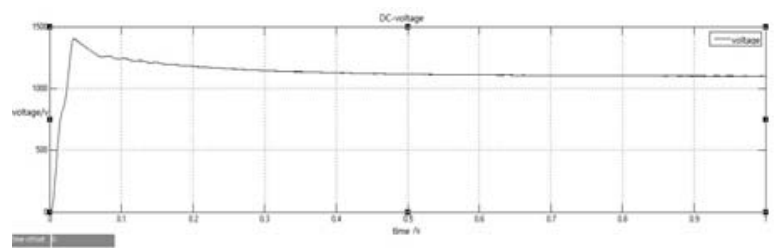

FIGURE V. WAVE OF DC-LINK VOLTAGE

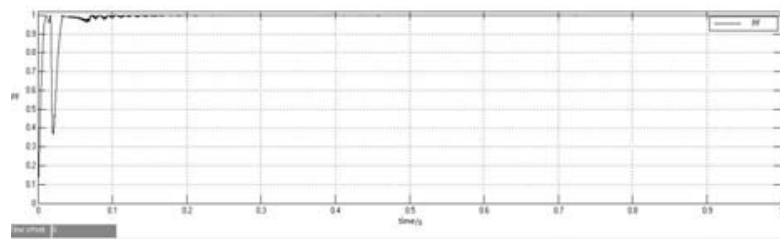

FIGURE VI. WAVE OF POWER FACTOR

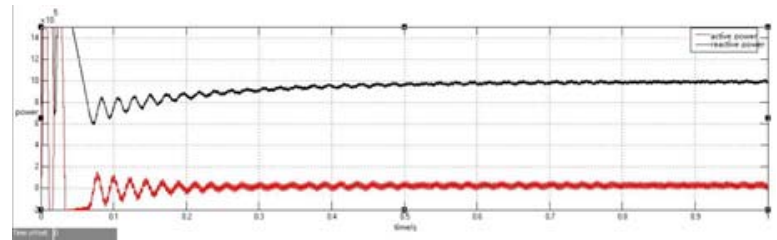

FIGURE VII. THE WAVE OF ACTIVE AND REACTIVE POWER 


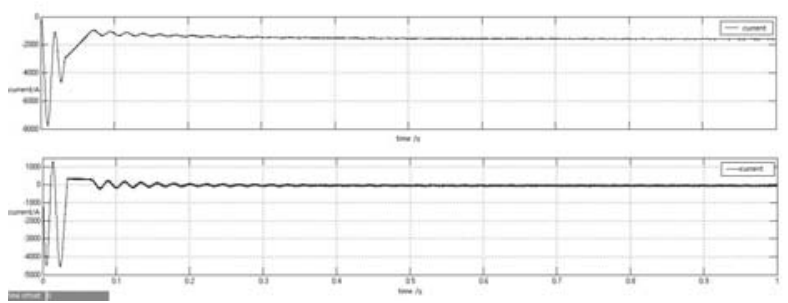

FIGURE VIII. THE WAVE OF $I_{D}$ AND $I_{Q}$ CURRENT

\section{CONCLUSIONS}

The paper introduces the working theory of the grid side converter of the full power wind power generator. And the control strategy is analyzed by Matlab/simulink. The system uses a dual-loop control method. In order to realize the decoupling control objective, the PI controller of the current inner loop is added to the corresponding feed forward compensation term. The paper has analyzed the feasibility and effectiveness of the power factor power-optimized control.

From the experimental verification result can be obtained, voltage oriented vector control of grid-side converter can be kept at a DC voltage and keep the power factor and stable operation at positive 0.9. While providing two-way flow of energy channels, maintaining a good control performance, achieve the purposes of grid-side power-optimized control. The simulation results show the effectiveness of the control strategy, but also proved that the grid-side converter control strategy used in this paper is feasible to meet requirements of the system.

\section{REFERENCES}

[1] Xin Zhang, Chong-wei Zhang. PWM rectifier and its control [M].Beijing: Machinery Industry Press, 2012.

[2] Hong-jun Wang, Dong-hua Zhao. Control strategy study of gridconnected inverter in direct-driven type wind power system [J]. Power Source Technology, 2015.139(6):1289-1292

[3] Yun-wen Zeng. The algorithm and application of frequency conversion speed regulation SVPWM [M]. Beijing: Machinery Industry Press, 2011.

[4] Liang,S.Q.and L.Li.Research of Control Method of Grid Voltage Orientation of Grid Side Converter of Doubly-fed Generator[C].Gongkuang Zidonghua-Industry and Mine Automation 2011.37(8):p.71-74.

[5] Feng Jie, Jing Huang. Three-phase PWM rectifier direct power control method of a new modulation[J]. power and electron technology,2012,40(4):9-11

[6] Serkan Dusmez, Qin Ling, and Bilal Akin,A New SVPWM Technique for DC Negative Rail Current Sensing at Low Speeds.IEEETransactions On Industrial Electronics VOL .62,NO.2, pp.826-831,Feb 2015.

[7] Wen-xiu Zhang, Hao-qian Lu, Juan Sun.Optimal Power Control Research of Direct-Driven Wind Turbine With Synchronous Generators[J].Electric machines\&control application 2015.42 (4):47-52

[8] Bhavan Jain,Shailendra Jain,R.K.Nema.Control strategies of grid interfaced wind energy conversion system;An overview Renewable and Sustainable Energy Reviews 47,983-996, 2015.

[9] Chun Li, Zheng-chun Yin, Lu-hua Zhang.Optimal Control for DC-link Voltage of Full Power Converters Used in Wind Power Generation[J].Journal of shanghai electric technology,2014,7(4):26-30 